\title{
Prof. Larry R. Kaiser: empowering your colleagues with trust and freedom
}

Received: 21 November 2018; Accepted: 13 December 2018; Published: 27 December 2018.

doi: 10.21037/jhmhp.2018.12.02

View this article at: http://dx.doi.org/10.21037/jhmhp.2018.12.02

\section{Expert's introduction}

An internationally renowned academic executive, thoracic surgeon, researcher and author, Larry R. Kaiser, MD, FACS currently serves as the CEO of Temple University Health System, Senior Executive Vice President for Health Affairs, and Dean of the Lewis Katz School of Medicine at Temple University.

Career:

* The Lewis Katz Dean at the School of Medicine;

* Senior Executive Vice President for Health Affairs, Temple University;

* President and CEO, Temple University Health System;

* Professor, Thoracic Medicine and Surgery.

Education:

- Residency, Thoracic Surgery, University of Toronto, Canada, 1985;

* Residency, Cardiovascular Surgery, University of Toronto, Toronto, Canada, 1984;

* Postgraduate Research Fellowship, Surgical Oncology, 1982;

* Residency, Surgery, University of California, Los Angeles, CA, 1979;

* Internship, Surgery, University of California, Los Angeles, CA, 1978;

* MD, Tulane University School of Medicine, New Orleans, LA, 1977;

* BS, Tulane University, New Orleans, Louisiana, 1973.

In light of Prof. Kaiser's rich experience in hospital management, Journal of Hospital Management and Health Policy $(7 H M H P)$ is honored to have an exclusive interview with him as a highlight for the featured column "Meet the Experts: the Cutting Edge in Hospital Management" (Figure 1).

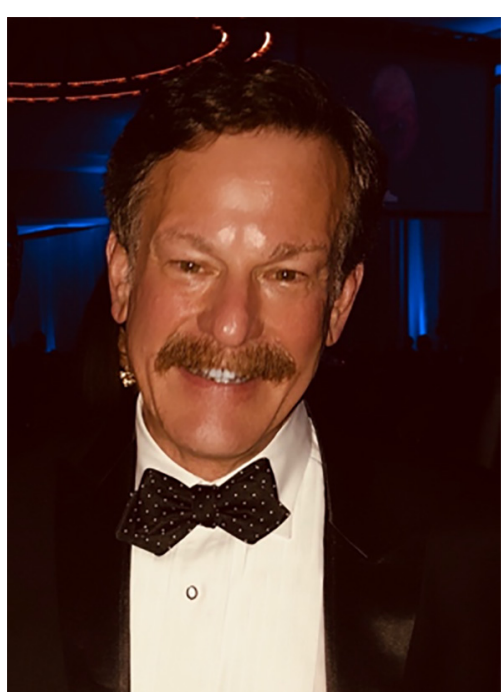

Figure 1 Prof. Larry R. Kaiser.

\section{Interview}

Get to know more about Prof. Larry R. Kaiser

JHMHP: You used to be a thoracic surgeon before serving as the taking on the management role in Temple University Health System. What actually makes you interested to take on the management role? Prof. Kaiser: For the record, I remain a thoracic surgeon fully credentialed and board certified and I have a limited clinical practice. I became interested in a leadership role a number of years ago when I was still on the faculty at the University of Pennsylvania. As I was offered small leadership roles I became very interested in the financial aspects of the practice of surgery and was being offered the opportunity to interview for chairmanship jobs. It was clear to me that I had the tools to be a leader and felt that I had something to contribute. 
JHMHP: What do you regard as the key qualities of being a doctor and being an administrator in the healthcare field? What are the similarities and differences in your opinion?

Prof. Kaiser: In both roles, one is called upon to make decisions often without complete information available. Certainly, in the operating room, decisions need to be made in a very timely fashion, often without any significant period of contemplation. In an administrative role, decisions may be made after some period of reflection and contemplation but too many people get bogged down in trying to be too analytical. I knew I was capable of making a decision.

\section{The day of a hospital administrator}

JHMHP: What is your daily routine as the CEO of Temple University Health System?

Prof. Kaiser: It really depends since I have multiple roles. On some days, I need to be at the main campus of the University for a meeting of the Council of Deans or a meeting of the President's cabinet. I also am required to attend a number of committees of the Board of Trustees of the University and the Board meetings. On other days, my role as Dean takes precedence meeting with the Sr. Associate Deans who are my direct reports. In addition, there are a number of meetings dealing with the business of running the Health System, such as my meeting with the hospital CEOs. My day starts at 5:00 AM with a workout and I'm at my desk by 8:00 after dropping my son off at school. On some days, I'm here for 7:00 AM meetings. I often have evening activities such as dinners with colleagues or other meetings.

\section{JHMHP: Apart from your administrative roles in}

Temple University, you are also the member of a number of medical associations. How do you manage time to fulfil all your duties and cope with the pressure? Prof. Kaiser: I live in a number of worlds, the surgical world, the hospital and health system world and the medical school world and there are meetings an organization associated with each of those entities. I am fortunate to sit on an important committee of the American Hospital Association. I'm a member of the Council of Deans of the Association of American Medical Colleges, I sit on the board of the Association of Academic Health Centers and I belong to all of the major surgical organizations including the American College of Surgeons, the American Surgical Association, the Society for Thoracic Surgeons, and the
American Association for Thoracic Surgery. I don't tend to feel any pressure.

\section{The essence of hospital management}

JHMHP: What do you regard as the key elements in health system management?

Prof. Kaiser: It takes a great team of individuals to run a health system and putting that team together and having it function well really is the key element. But even more critical is giving those talented people both the responsibility and the authority to do their job. I am not a micromanager, not even close. I rely on people to do their jobs and I don't interfere. I ask that they keep me informed and unless someone is doing something that will take down this organization I don't interfere nor do I second guess.

JHMHP: How would you comment on the hospital management system in the US in general?

Prof. Kaiser: Thanks to the efforts of the American Hospital Association, most hospitals in this country are very well managed. We are seeing increasing consolidation among hospitals in many markets including our own. This has resulted in the formation of large health systems in many cities across the country.

JHMHP: US News \& World Report listed Temple's Lewis Katz School of Medicine among the top research schools in the US. From your point of view, how do you see the status of the Temple University Health System in the US? Which areas do you think it is superior/ inferior to other health systems in the US?

Prof. Kaiser: On a per capita basis, we have done very well with research funding and we have seen a continued increase in that funding. Our ratio of faculty to students also is quite good. Where we have struggled in those ratings is with the peer assessment or reputational score. Many people still think of Temple in a negative light though the reality is quite different. Our medical school provides an outstanding education, we are able to accept high quality applicants and they are very competitive for outstanding residencies.

JHMHP: From your point of view, what is the most important thing when determining the direction of a hospital's development?

Prof. Kaiser: It has become increasingly clear that the centrality of medical care is moving away from the inpatient setting to outpatient care and even to more care done in the 
home. Hospitals have to be able to adjust to the decrease in revenue that comes with that shift away from inpatient care, the biggest source of revenue. Creating a robust outpatient experience that includes easy access for patients to see a physician, urgent care centers and ambulatory surgical centers is critical. More and more surgical procedures previously only done as inpatients are now moving to the outpatient setting.

JHMHP: We all know it is not easy to maintain an internationally-recognized hospital management system. For example, distributing resources, evaluating the outcomes and efficacy of service or treatment and so on. What strategies or methods have been used to make it possible?

Prof. Kaiser: We benchmark all of our efforts to national data of peer institutions collected via Vizient that includes the former University Health and Hospital Consortium (UHC). These data include quality benchmarks, mortality and efficiency domains. We also submit data to a trauma registry, the Society of Thoracic Surgery database and the National Surgical Quality Improvement Program (NSQIP) program of the American College of Surgeons. Knowing how we compare with peer institutions is critical for our ongoing process improvement efforts.

JHMHP: How do you train your staff and how do you evaluate the performance/standard of your staff in the Temple University Health System?

Prof. Kaiser: We have a very thorough on-boarding and orientation for new staff when they start and have ongoing educational programs. Staff are evaluated on an ongoing basis by their supervisor and feedback is provided. We have an incentive program that rewards outstanding performance on a yearly basis. Our nursing department has an extensive "internship" program for new graduates that allows them the opportunity to consolidate their knowledge and learn to apply it clinically in a challenging setting.

\section{Memorable moments in Temple}

JHMHP: We believe each hospital will come across a time when patients are not satisfied with the services or treatments provided by the hospital. What is the system of the Temple in handling patients' feedbacks or complaints? How did you resolve their problems? Any memorable cases?
Prof. Kaiser: We have a chief patient experience officer who is charged with dealing with patients complaints. These complaints may come in via phone calls, direct discussion with the nursing staff or letters sent to either me or the hospital administration. We deal with every complaint until the issue is resolved. We also have patient advisory councils in each of our hospitals to listen to patients advising us on what we can do differently and better.

JHMHP: Over the years, what challenges have you encountered when you manage the Temple University Health System? Any interesting stories?

Prof. Kaiser: Our greatest challenge is dealing with an underserved population who tend to use our Emergency Room as their primary source of medical care since many of these people lack a primary care physician. By far, our biggest payer is the federal government under both the Medicaid and Medicare program. Our commercial book of business is inadequate to cast shift enough money to cover the shortfall that results from what the government payers pay. One response to addressing the overuse of our emergency room has been the placement of a Federally Qualified Health Center immediately adjacent to the emergency room where patients may be sent if the level of care they require does not rise to the level that needs ER care.

\section{Current status and future prospects}

JHMHP: Are there any important projects underway in the Temple University Health System in 2018 that you would like to share with our readers?

Prof. Kaiser: We are currently in a restructuring process that will allow us to continue to be successful as a health system as we recognize some of the challenges that we and other systems face. In addition, we continue to look at ways to become more efficient and take cost out of the system without compromising patient care. We are looking at all of our clinical programs to see where we can become more efficient. We recently outsourced our call center to make it easier for patients to access our physicians.

JHMHP: How do you see the future of the Temple University Health System? What do you aim to achieve in 10 years' time?

Prof. Kaiser: We are in a market that is consolidating around us and we essentially have been "left out". The 
role that Temple University Hospital plays as a safety net hospital likely will not change since it is a critical one for the city of Philadelphia. We may see some changes in some of the components of our health system.

\section{Words of wisdom for the youth}

JHMHP: You have been named as one of " 112 Physician Leaders of Hospitals and Health Systems to Know". As a successful CEO, what would be your advice to younger generations (like younger physicians, nurses or students) in pursuing their dreams?

Prof. Kaiser: Set goals, work hard, become proficient and recognized in some area in which you are interested and passionate. Be collaborative and recognize that medicine is practiced optimally as a team. Recognize the contributions made by other team members.

\section{Acknowledgments}

We would like to express our sincerest gratitude to Prof. Larry R. Kaiser for sharing his insights and opinions with us. Funding: None.

\section{Footnote}

Provenance and Peer Review: This article was commissioned by the editorial office, Fournal of Hospital Management and Health Policy for the series "Meet the Experts: the Cutting Edge in Hospital Management". The article did not

doi: $10.21037 /$ jhmhp.2018.12.02

Cite this article as: Cheung M. Prof. Larry R. Kaiser: empowering your colleagues with trust and freedom. J Hosp Manag Health Policy 2018;2:51. undergo external peer review.

Conflicts of Interest: The author has completed the ICMJE uniform disclosure form (available at http://dx.doi. org/10.21037/jhmhp.2018.12.02). The series "Meet the Experts: the Cutting Edge in Hospital Management" was commissioned by the editorial office without any funding or sponsorship. Mike Cheung reports that he is a full-time employee of AME publishing company (publisher of the journal). The author has no other conflicts of interest to declare.

Ethical Statement: The author is accountable for all aspects of the work in ensuring that questions related to the accuracy or integrity of any part of the work are appropriately investigated and resolved.

Open Access Statement: This is an Open Access article distributed in accordance with the Creative Commons Attribution-NonCommercial-NoDerivs 4.0 International License (CC BY-NC-ND 4.0), which permits the noncommercial replication and distribution of the article with the strict proviso that no changes or edits are made and the original work is properly cited (including links to both the formal publication through the relevant DOI and the license). See: https://creativecommons.org/licenses/by-nc-nd/4.0/.

(Science Editor: Mike Cheung, JHMHP, jhmhp@amegroups.com) 